\title{
Enfim, o SciELO
}

Chegamos ao último número do ano e com ele vimos ao leitor informar como se desenrolaram os eventos de 2001. Iniciamos o volume 67 com grandes expectativas quanto à evolução de nossa revista, tanto em sua qualidade científica, quanto em sua profissionalização administrativa. Pela quantidade de artigos originais que vínhamos recebendo a cada mês, já em 2000, imaginávamos que poderíamos ampliar sobremaneira nossa capacidade editorial. Entretanto, o número de trabalhos recebidos suplantou em muito nossas melhores projeções. Com isso, conseguimos aumentar o tamanho total da revista em mais de 200 páginas (fig.1), um acréscimo de cerca de $47 \%$, sendo que mais de $75 \%$ deste em artigos originais (fig.2).

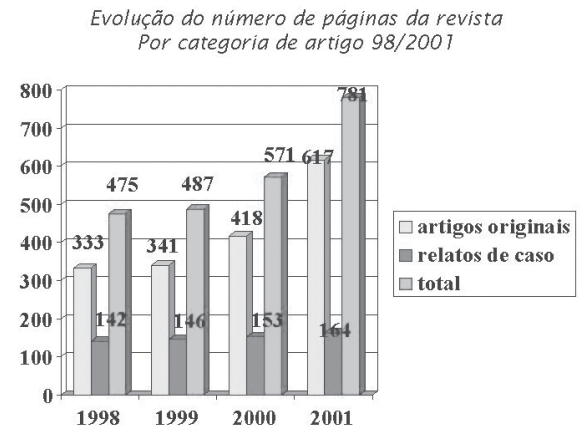

Fig.1

$$
\text { Aumento do número de páginas da revista }
$$
98/99 - 99/2000 - 00/2001

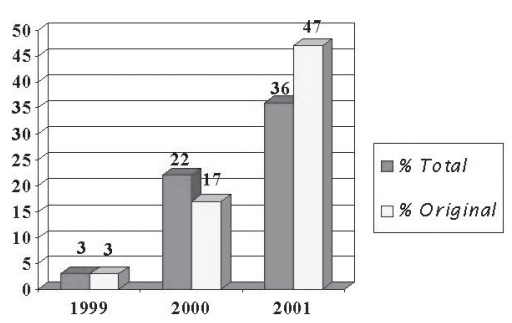

Fig. 2

Poderíamos supor que este aumento de páginas seria conseqüente a uma política de facilitação da avaliação dos trabalhos e que levaria a uma queda de qualidade dos artigos. No entanto, o que constatamos foi um aumento do porcentual de artigos recusados por nosso corpo editorial (35\%), o que mostra rigor na avaliação e uma enorme oferta de trabalhos controlados, randomizados e prospectivos de excelente qualidade (fig.3). Como conseqüência mais marcante do aumento do número de páginas da revista, percebemos uma redução acentuada no tempo transcorrido entre o recebimento do artigo e sua publicação após aceito. Atualmente os trabalhos aguardam cerca de 2 a 3 números para serem publicados, numa média de cerca de 5,6 meses (fig.4).

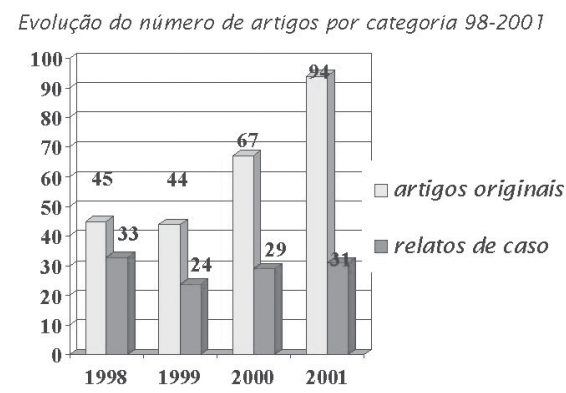

Fig.3

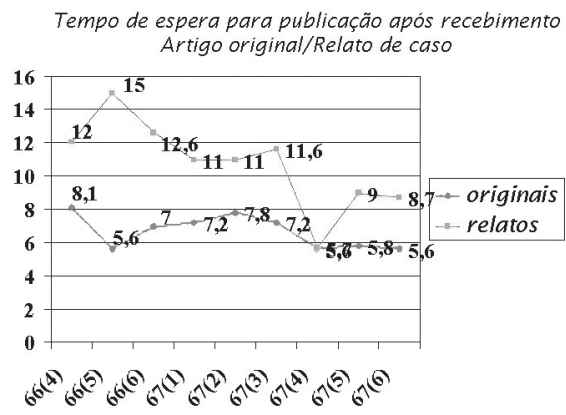

Fig.4

Afora os avanços de expediente, introduzimos neste número as figuras coloridas, que vão se tornar rotineiras nos próximos volumes e, para isso, contamos com a remessa de ilustrações que valorizem ainda mais os trabalhos científicos.

Para conseguirmos a qualidade alcançada até agora, pudemos contar com a ajuda segura de nosso corpo editorial que, por motivos bastante óbvios, está sendo elevado para 104 nomes, sendo que passamos a contar com um corpo editorial internacional, capitaneado pelo Dr. Eugene Myers e por Consultores Externos de outras áreas como Infectologia, Neurologia, Reumatologia, Patologia e Ética. Em breve pretendemos contar com profissionais em estatística para auxílio de nosso corpo editorial. Como fator negativo, sentimos este ano a falta de uma maior participação de todas as unidades da federação no envio de trabalhos para publicação (fig. 5). 


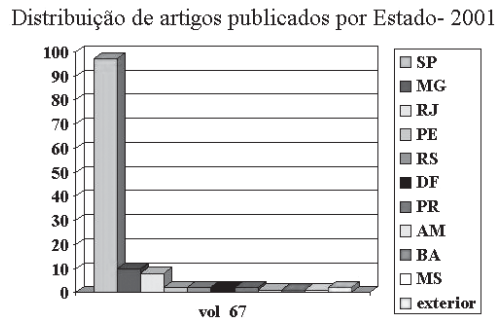

Fig. 5

Entendemos que está concentrada na região Sul e Sudeste a maioria dos serviços de ensino e pesquisa em ORL, assim como, o maior número de médicos da especialidade (cerca de 70\%). Ainda assim, clamamos por uma participação mais ativa dos nossos eméritos mestres de todos os Estados para que compartilhem com todos nós os seus conhecimentos, remetendo-os à nossa revista.

O ano transcorreu bem, mas a grande notícia estava por vir em outubro e vinha de um dos mecanismos de indexação que mais nos interessava, seja do ponto de vista editorial ou de visibilidade externa para nossos artigos: o

\section{Scientific Electronic Library Online}

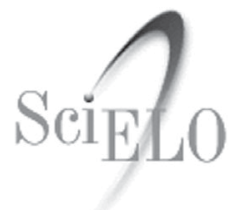

Este projeto, patrocinado pela FAPESP e gerenciado pela BIREME - Centro Latino Americano e do Caribe de Informação em Ciências da Saúde, tomou sob sua responsabilidade a indexação, avaliação permanente e disponibilização de artigos de periódicos científicos brasileiros, de todas as áreas do conhecimento, com o objetivo de aumentar a visibilidade da produção científica nacional, facilitando os envios de dados entre o SciELO e as bases de dados internacionais, além de tentar estabelecer projetos em comum com os serviços de busca internacionalmente conhecidos e utilizados para pesquisa, como o PubMed Central. Nesta biblioteca estão incluídos alguns dos títulos que já estavam indexados na LILACS e que mostraram padrão de qualidade internacional, e que cumpriam os critérios de seleção e avaliação de periódicos proposto pelo documento de critérios adotado pelo SciELO, baseado nos critérios adotados pelas bases de dados internacionais, como o Index Medicus. Até o momento, apenas 35 periódicos da área de saúde estão incluídos no SciELO, sendo que apenas 12 na área médica e a Única revista de ORL nacional que conseguiu sua aprovação foi a Revista Brasileira de Otorrinolaringologia. Entendemos que isto é motivo de enorme orgulho para a comunidade otorrinolaringológica nacional, mas percebemos a grande responsabilidade que passamos a ter ao sermos os solitários representantes da pesquisa tupiniquim na ORL junto aos nossos pares estrangeiros. Acreditamos que participando desta agência, estaremos aptos para, com o aumento de citações internacionais, solicitarmos nosso ingresso no ISI (editorial 67(3)).

Aproveitando o fato de falarmos em citações, volto a lamentar a postura que temos tomado como povo. Percebemos em todos os momentos de nossa vida acadêmica, o quanto temos desdenhado a cultura e pesquisa brasileiras. Quando os colegas preparam apresentações públicas, se esmeram em recolher dados de revistas estrangeiras e pouco se lembram de nossa produção interna. Será que ela não conta? Não seria isto apenas reflexo do que pensamos sobre nós mesmos como país? Sempre o de fora é melhor! Quando vamos nos dar o devido valor? Recentemente, em 12 de fevereiro deste ano, o Council on Foreign Relations (Conselho de Relações Internacionais) dos Estados Unidos - formado pelos mais influentes intelectuais e empresários americanos - publicou um memorando ao Presidente Bush, a todos os membros principais do governo americano e aos mais influentes membros do congresso americano sobre as relações dos Estados Unidos com o Brasil. O estudo é assinado por 23 personalidades intelectuais americanas. Diz a carta ser o Brasil "a maior potência econômica e líder entre os mercados emergentes mais avançados. A economia brasileira é o dobro da russa, tão grande quanto a da China e duas vezes maior do que a da Índia... Com mais de US\$1 trilhão em Poder de Paridade de Compra, o Brasil é a quinta economia do mundo depois dos EUA, China, Japão e Alemanha...." Parece que lá fora estão acreditando mais no Brasil do que aqui. As companhias multinacionais da Espanha e Portugal tem mais investimentos aqui do que em seus próprios países. Não teríamos que nos dar mais o respeito? A nossa Sociedade de especialidade é pelo menos uma das três maiores do mundo, temos o terceiro Congresso de Otorrinolaringologia do mundo, atrás apenas do Meeting da Academia Americana e do Mundial, formamos cerca de 250 novos especialistas/ano e a nossa produção científica na área já foi considerada por Peter Alberti, ex-presidente da Federação Internacional de Sociedades Otorrinolaringológicas - IFOS - como a segunda do mundo. Talvez seja a hora de prestarmos mais atenção no que temos produzido e comunicado. A inteligência também pode morar ao lado.

Em suma, consideramos que vivemos um grande ano acadêmico. Com a ajuda de todos os autores, editores e do grupo de produção editorial e gráfica conseguimos produzir mais um volume que nos deixou bastante entusiasmado e com o qual achamos que todos puderam se divertir, esperamos continuar com a colaboração de todos que tem nos acompanhado e damos desde já as boas vindas aos que pretendem ingressar na família da Revista Brasileira de Otorrinolaringologia no ano de 2002.

Felicidade e Saúde a todos

Henrique Olival Costa

Editor Executivo 